\title{
Aging and Human Rights: a Rights-Based Approach to Social Work with Older Adults
}

\author{
Carole Cox $^{1}$ (D) $\cdot$ Manoj Pardasani ${ }^{1}$
}

Published online: 16 August 2017

(C) Springer International Publishing AG 2017

\begin{abstract}
The world is aging, and this demographic shift necessitates social workers with gerontological knowledge and expertise. The physiological, social and economic changes that commonly impact older adults and frequently contribute to dependency make them vulnerable to having their human rights violated. By focusing on needs rather than rights, the human dignity, security, and autonomy of the individual can be easily ignored. Social workers involved at the micro, mezzo, and macro levels can play key roles in ensuring that private problems are perceived as public issues and that rights are recognized. This paper focuses on policies and practice in the USA impacting older adults and the ways in which social work involvement can be critical to ensuring well-being and social justice for those among the most vulnerable in society.
\end{abstract}

\section{Keywords Aging $\cdot$ Rights $\cdot$ Social work $\cdot$ Social justice}

The world is aging. By 2050, the global population of those 65 and older is expected to triple (United Nations 2013). The USA reflects this shift as in 2030 persons 65 and older will compose $20 \%$ of the population, while by 2050 , the global population of those 65 and older will compose more than $21 \%$ of the world's population (Ortman et al. 2014). As noted by both the International Federation of Social Workers (IFSW 2012) and the National Association of Social Workers (NASW 2014), this population shift has created a greater demand for professionals with specialized knowledge and expertise in aging.

Carole Cox

ccox@fordham.edu

1 School of Social Service, Fordham University, New York, NY, USA
As people age, they encounter transitions that affect all areas of their lives. Retirement often means changes in relationships as well as economic status. Widowhood and the loss of close relatives and friends can induce intense feelings of grief that can be numbing without skilled and sensitive interventions. Physical changes can limit mobility, while mental impairment can impede overall functioning. Such changes frequently impact relationships as traditional roles are altered. Consequently changing family structures mean that older adults are often left with limited supports. A critical repercussion of these life changes that is often overlooked is the impact that they have on the human rights of the older person.

The Universal Declaration of Human Rights (UDHR) passed by the United Nations in 1948 includes five types of rights (Wronka 2008): Article 1 Human Dignity; Article 2 Nondiscrimination; Articles 3-21; Civil and Political Rights; Articles 22-27 Economic, Social, and Cultural Rights; and Articles 28-30 Solidarity Rights. The first set of rights (Articles 2-15) relates to political and individual freedoms restricting the interference of governments with the individual, while Articles 16-27 focus on the right to an adequate standard of living including health and wellbeing, food, clothing housing medical care, and necessary social services. The third set of rights (Articles 28 through 30) promotes intergovernmental cooperation on global issues such as the environment and development, international peace, and international distribute justice.

Social work is a human rights profession with the principles of human rights, dignity, and social justice forming its core (IFSW 2014). A key social work challenge is the balancing of human rights with needs while supporting the empowerment and self-determination of people. Given the transitions encountered by persons as they age and the impact that these may have on well-being and autonomy, this paper focuses on key policies 
impacting older adults in the USA, their relationships to human rights, and responding social work challenges.

\section{Rights and Needs}

Human rights are frequently confused with needs although the two are clearly distinguishable. Tangible needs exist as phenomena that can be objectively identified and measured such as needs for food, housing, support, or income (Ife 2012). However, needs can also be subjective, wherein society decides whether they actually exist. In contrast to human rights, which are constant, social values and perspectives are influential in determining needs.

Social workers often determine needs by measuring them through "needs assessments" that decide whether supports or services are warranted and how they may or should be met. Such needs are then filtered through the prism of competing resources where one vulnerable group may benefit at the expense of another dependent upon the values and viewpoints of policy makers and providers.

In contrast to needs, the universality of human rights and their indivisibility means that they are substantiated in themselves and are not dependent on social values or perspectives. Moreover, human rights provide the mandate to fulfill human needs with social policy acting as the means for attaining them. Consequently, social workers can play major roles in assuring that with policy and practice, needs are reframed and treated as basic human rights to which each individual is entitled.

\section{Human Rights Conventions and Older People}

Subsequent to the Universal Declaration of Human Rights, several special conventions were adopted by the General Assembly of the United Nations focused on specific population groups including the Convention on the Elimination of All Forms of Discrimination against Women, the Convention on the Rights of the Child, Convention on the Protection of the Rights of All Migrant Workers and Members of their Families, and the Convention on the Rights of Persons with Disabilities. Countries ratifying conventions are legally bound to adhere to their standards.

To date, there has not been a convention on the rights of older people. Among the arguments against a convention are claims that existing human rights documents cover the rights of older persons (Megret 2011); and that experience shows that conventions do not lead to real social change, and therefore, advocates should focus on assuring the implementation of existing treaties, conventions, and principles (Doron and Apter 2010).

In 1991, the United Nations issued The Principles of Older Persons (UN 1991) which detailed five areas in which the rights of older people needed to be prioritized and guaranteed: independence, participation, care, self-fulfillment, and dignity. Regional meetings and country reports on the status of older people continue to be held, and the United Nations has developed a standing committee on the rights of older people (Help Age International 2010).

The Madrid International Plan of Action on Aging (MIPPA, United Nations 2002) presents the rights of older persons, but although it has been endorsed by the General Assembly of the United Nations, in contrast to conventions, it is not binding on member states. Governments have only a moral responsibility to adhere to its recommendations, which focus on core issues associated with the rights and quality of life of older people. These rights include governments promoting human rights instruments and supporting decision making among older people; enabling people to work as long as they can and choose, retiring with adequate pensions; assuring that older people have access to the same preventive, curative, and rehabilitative care as others; and ensuring that older people have access to decent housing, supports, and are free from neglect, abuse, and violence. Accordingly, these rights must not be perceived as only a moral responsibility, as doing so absolves governments and societies from committing to progressive change or concrete actions (UN 2002).

In 2010, the General Assembly of the United Nations established the Open-Ended Working Group on Aging. The group is charged with considering existing international frameworks of human rights of older people, identifying gaps in policies and services, and devising ways of addressing them. Among the major challenges it is dealing with are discrimination, poverty, and violence and abuse. The group is also exploring the possibility of developing an international legal instrument to promote the rights and dignity of older persons (www.ohchr.org).

Based on the recent assessment of global policies and the situation of older people, many gaps continue to exist with regards to their rights and countries' commitment to them. Rosa Kornfeld-Matte, the Independent Export on the Rights of Older Persons to the United Nations, supports the need for a new legal instrument to support the rights of older persons (UN General Assembly, 2016). A dedicated instrument such as a convention would clarify these rights and strengthen the accountability of governments to adhere to them.

\section{The Rights-Based Approach}

The human rights approach looks beyond the individual and the issues they are facing to the structure and culture of the society itself and the ways in which it is contributing to problems. The approach makes private troubles into public issues (Ife 2012) as it goes beyond addressing individual needs and advocates for structural and cultural changes at both mezzo and macro levels with needs being perceived as basic human rights (Libal and Harding 2015). 
A key difference between rights-based and needs-based analysis is that the needs-based approach measures success according to the attainment of specific goal, while the rightsbased approach assesses success according to the realization of human rights with the recognition that individuals and groups, rights holders, are entitled to them and that dutybearers are obligated to meet them (Gatenio Gabel 2016).

Two values, benevolence and paternalism, play key roles in social work with older adults. Benevolence refers to kindness and promoting the good of others, while paternalism refers to interfering with an individual's right to carry out their own decisions for their own good. Both values assume that persons are worthy of assistance and that the person offering help is committed to their wellbeing and best interests. However, paternalism can seriously conflict with a client's right to self-determination even when the intention is to protect the person from harm. As noted by Reamer (2005), for paternalistic interference to be justifiable, social workers must demonstrate hat clients would otherwise face dire, perhaps irreversible consequences.

\section{Guardianship}

No policy has greater impact on the rights of the individual for liberty and security than that of guardianship. Guardianship deems that an individual is incompetent to make decisions on his or her own behalf for their best interests. If no immediate relative or friend is available to make such decisions, courts, under the doctrine of "parens patriae," have the ability to assign guardians to protect these persons and their property. Although there are no precise national data in the USA on the number of older adults with a guardian, the most recent estimate has it ranging from just under one million to more than three million persons (Uekert and Van Duizend 2010).

Guardianship can be requested by anyone with state laws regulating the actions that a guardian can make on their own and those that require court approval. However, as there is little monitoring of guardians, there are few safeguards for the older person. Having a guardian removes the individual's control over his or her life. Moreover, there are few guarantees that the guardian will uphold or fulfill this role or that the interests of the ward will be supported.

A major concern in guardianship proceedings is the lack of a standardized uniform measure for assessing competency or regulations as to who can make the judgment. Thus, one may be judged incompetent in one state and competent in another. The lack of homogeneity among competency evaluations and the qualifications of persons making these assessments puts many at risk of abuse or neglect (Moye and Naik 2011). In addition, the absence of consistent oversight of a guardian further increases the risk of malfeasance.
Although some may require only limited guardianship with regards to medical decisions or estate management, the tendency is to grant full guardianship, giving the guardian control over all aspects of the person's life. As such, the guardianship process focuses on the weaknesses and failings of the older person (Wright 2014). By focusing on failings, the rights of human dignity, security, and participation are seriously threatened as strengths are ignored and the person is at imminent risk of losing control of his or her life.

The rights-based approach offers a conceptual framework for social work involvement in the guardianship process. At the micro level, social workers can ensure that assessments explore individual strengths and resiliency of the proposed ward and that the wishes of the person are recognized. Involvement at the mezzo level can help ensure that those assuming the role of guardian are vetted and that the interests of the person are kept paramount through proper oversight by the court. Macro involvement demands that social workers become involved as advocates and provide ethical oversight working towards improving the system to ensure that it is sensitive to and reflective of human rights. At the mezzo and macro levels, social workers can help create structures that develop guidelines, monitor the guardian relationship, raise community awareness, and provide training for all involved.

\section{Employment}

Employment provides a vivid example of the way in which age alone can impact human rights. Employment opportunities decline with age, with older workers commonly facing discrimination in the workplace (Smith Fitzpatrick 2014). Moreover, once unemployed, older workers are more likely to face long-term unemployment that their younger peers, and if rehired are likely to have earnings that are lower than their previous earnings (GAO 2012). Consequently, rights to employment are ignored and security threatened.

The Age Discrimination in Employment Act (ADEA) of 1967 applies to companies of 20 employees or more and is intended to prevent age discrimination in hiring, firing, promotions, training, and other conditions of employment. Data on charges made under the ADEA by those 55 and older have progressively increased since 2000 (von Schrader and Nazarov 2015) with harassment, discipline, and intimidation growing from $10 \%$ of charges in 2000 to $30 \%$ in 2010). However, proving age discrimination is difficult, as the plaintiff must show that age is the motivating factor. Thus, data from the Equal Employment Opportunity Commission (EEOC) show that only $2.7 \%$ of cases taken to the EEOC were found to show reasonable cause of discrimination (EEOC 2015).

Social workers in employee assistance programs (EAPs) have the opportunity not only to counsel employees but to also bridge the gap between employees and employers. They can educate employers on the impact of workplace policies 
and procedures on older employees and suggest changes that increase everyone's well-being (Ottenstein and Jacobson 2006). Consequently, social workers can become involved in actually changing the structure and environment of an organization to make it more sensitive to discriminatory actions and more responsive to older adults.

Persons with cognitive impairment are at particular risk of discrimination in the workforce. Employers tend to make little accommodation for these employees even though they could often continue to work in varying capacities (Alzheimer's Association 2011). Instead, they are frequently let go at the beginning stages of impairment with employers often unsure of how to counsel them or discuss their symptoms (Cox and Pardasani 2013).

The rights of employed caregivers, the majority of whom are women, are at risk due to loss of income and benefits as they reduce work hours, decline promotions, and take early retirement in order to provide care (AARP and NAC 2015). The Family and Medical Leave Act (FMLA) remains the primary policy to support these caregivers. The act offers up to 12 weeks of unpaid leave to employees to provide care for a parent, child, or spouse. However, it is restricted to companies with 50 or more workers and applies only to those who have been employed at least 12 months. With $40 \%$ of the workforce ineligible for its benefits (www.nationalpartnership.org), many are forced to struggle to combine caregiving and employee roles.

Social workers at the micro level are needed to counsel employees dealing with the illness, caregivers struggling to combine care and work, and employers seeking to understand the ramifications of dementia. Mezzo level interventions may include developing work place support groups and educational programs on dementia as well as different work possibilities such as flextime and telecommuting. At the macro level, advocacy for policies that protect and support rights for employment and security is essential with particular attention given to the expansion of the FMLA, which can support the well-being of the entire family.

\section{Income}

Having a decent standard of living is a basic human right (UNDHR, Articles 22 and 25). However, poverty among the elderly remains a reality. In 2013, half of all people on Medicare in the USA had incomes less than \$23,500, which is equivalent to $200 \%$ of the poverty level for 2015 (Cubanski et al. 2015). Those older adults most likely to be in poverty are over the age of 80, women, Blacks, and Hispanics and those with relatively poor health (Cubanski et al. 2015).

Social Security has helped to reduce poverty among older persons in the USA and is a primary source of income for $38 \%$ of the elderly in this country and the main source of income for more than one third of African Americans and Hispanics
(SSA 2014). However, these benefits do little for the economic security of these minority groups as their rates of poverty, $19 \%$ for older African Americans and $18 \%$ for older Hispanics, are more than double the $8 \%$ rate for older whites (Waid 2016).

Supplementary Security Income (SSI) is available to many older persons whose income is below the poverty line. In 2015 , the maximum annual amount for an individual was $\$ 8804$ and for a couple $\$ 13,205$ (SSA 2015). Given the cost of living in the USA, these amounts are often not sufficient to cover usual living expenses causing many to remain economically insecure with incomes at or below $250 \%$ of the federal poverty level (NCOA 2016).

Proposals that would reduce Social Security benefits would force even more into poverty. The absence of a Cost of Living Adjustment in 2015, the first time in 40 years, failed to recognize the buying patterns of older adults who spend more of their budgets on health care, food, and housing than younger persons (AARP 2015). Raising the retirement age for full Social Security benefits would place an undue burden on specific groups, African American men and those with poor health, who are most dependent on these benefits (Ghilarducci and Moore 2015).

At the micro level, social work knowledge and counseling skills are important in educating persons about Social Security and other benefits and assisting with access when necessary. At the mezzo level, social workers can work towards ensuring that such programs and benefits are clear and understandable to all groups of older adults so that accessibility is actually strengthened. However, social work contributions may be most important at the macro level as they advocate for policies that support the economic well-being of older adults. Documenting the struggles associated with limited incomes, giving public testimony at hearings on the economic hardships that many face, and supporting the advocacy efforts of associations working for the security and rights of older adults are key areas for advocacy and involvement.

\section{Health}

Health and the right to health care in the event of illness, disability, or old age is detailed in Article 25 of the UNDHR. The two major programs in the USA working to ensure this right for older adults are Medicare and Medicaid.

Medicare, the national governmental health insurance programs for persons over 65 , maintains an acute or short-term focus rather than addressing the chronic care needs of older adults. Part A offers hospital insurance, and Part B, an optional program that persons can purchase, covers physician services and some outpatient care. Part D covers outpatient prescriptions, while Part $\mathrm{C}$ is a private insurance plan offered through health maintenance organizations. 
Medicare's coverage of long-term care, whether in the community through home care and home nursing or in nursing homes, remains limited. In order to receive homecare, a person must be homebound, require skilled care, be certified by a physician, and receive care from a Medicare-certified agency, with care limited to 21 days or less (Medicare 2015). In addition, assistance is offered only if the beneficiary is expected to improve, a requirement that is difficult for many older recipients with chronic illness to meet.

Medicare coverage for skilled nursing homes is limited. Eligibility depends on being admitted to a nursing home after a qualifying hospital stay with the physician documenting that daily skilled care is required by a medical condition. Full coverage is available for 21 days with partial coverage for the next 100 days. Consequently, those needing long-term care in a skilled facility are not covered, seriously impacting their rights to appropriate health care.

Medicaid, Title XX of the Social Security Act, provides health care for those, including the elderly, who fall below the poverty line. The federal government provides federal matching dollars to the states for services for those eligible with the average federal share about $57 \%$ of program costs (Kaiser Family Foundation 2015). In order to meet eligibility criteria, many must "spend down" their assets and savings, which can further compromise their economic well-being.

Medicaid is the principal provider of long-term health care in the USA, covering nearly $50 \%$ of all nursing home residents and $62 \%$ of all other long-term services (Commission on Long Term Care 2013). Older persons and those with disabilities account for almost two thirds of its spending (Paradise 2015). Although nursing home care must be covered, other long-term care services, such as home care, are optional and decided by each state. States who offer the Medicaid Waiver Program are able to provide community care for those who would otherwise be in nursing homes. In comparison to those residing in nursing homes, persons living in the community have been found to have less depression, anxiety, and higher levels of wellbeing (Dragset et al. 2013).

Current proposals to cut the costs of Medicaid will affect both eligibility and services and exacerbate the growing gap in services. National data indicate a serious unmet need for home and community services with 120,000 elderly and disabled persons on waiting lists for an average of 10 months for services (Ng et al. 2010). Further cuts will escalate this unmet need and imperil the rights of many to obtain essential care and remain in the community.

Social work involvement in both the Medicare and Medicaid programs is necessary at all levels. At the micro level, social workers are critical to helping persons understand benefits, eligibility, and cumbersome application forms. Social workers play important roles in working with families to educate and support them during the critical phases often associated with changes in health status and subsequent program eligibility. At the mezzo level, social work involvement is needed to assure that health services are available and accessible for all groups of older adults.

At the macro level, the profession must become actively involved in actual policy development. Challenging regulations and processes that impugn the rights of older adults to adequate health care are critical to change. Through testimonials, letter writing, and use of the media, social workers can bring attention to the impact that health-care policy has on the health and rights of older adults.

\section{Most Vulnerable Groups of Older People}

Although age itself acts as a criterion for discrimination and human rights violations, within the aging population, specific subgroups are most vulnerable to having their rights violated. Among these groups are older women, lesbian, gay, bisexual, and transgender (LGBT) seniors, and immigrants. For each of these populations, social work involvement at the micro level through counseling and education can help to empower individuals as needs are reframed as human rights. At the more macro level, social work leadership and involvement can help assure that policies and institutions recognize and realize human rights.

\section{Older Women}

Throughout the lifespan, women face discrimination, and this continues into their later years. Around the world, 189 countries have formally recognized gender inequalities and have ratified CEDAW. The only six UN member states that have not ratified the convention are Iran, Palau, Somalia, Sudan, Tonga, and the United States. Gender inequality becomes even more profound as women age, become marginalized, and their well-being and security are threatened.

Women in the USA who have been married can expect to live as widows for 15 to 20 years. Older women are more likely to spend their later years alone and twice as likely as their male counterparts to be poor (Women's National Law Center 2014). Their lower paying jobs are often without benefits or pensions causing them to rely on Social Security as a sole source of income. However, their average payments are $\$ 4500$ less than those of men (Women's National Law Center 2014) with Social Security benefits constituting $90 \%$ of the income for women 65 and older (GAO 2012). In comparison to their male counterparts, a much larger proportion of women, $60 \%$ as compared to $20 \%$ of retired men, have insufficient income to cover their basic needs resulting in their having less financial security and greater financial worries (Rix 2013, Wider Opportunities for Women 2012). 
Women also struggle within the health-care sphere. As they tend to outlive men, they are more likely to develop chronic illnesses and impairments that impede functioning and change them from caregivers to care receivers (Kaiser Family Foundation 2011). They are also less likely than men to have the immediate support of a spouse and thus more likely to be dependent on formal support services to help them stay in the community.

Medicaid is a major resource for this assistance with women comprising 69\% of all Medicaid recipients (National Women's Law Center 2015). With the median cost of home care at approximately $\$ 3500$ per month and nursing homes at $\$ 7000$ per month (Genworth 2015), few are able to afford these programs. As the ability of older women to remain secure in their own homes is often dependent on the availability of benefits, their rights remain vulnerable.

\section{Lesbian, Gay Bisexual, and Transgender Elders}

The number of older LGBT adults in the USA is estimated at 1.5 to 7 million, and this number is expected to double by 2030 (Fredriksn-golsen et al. 2014). The combination of age and sexual orientation places the human rights of these individuals at particular risk of violation.

LGBT seniors are more likely to be in poverty than their heterosexual peers with the risk greatest among lesbian couples and transgender individuals (Badgett et al. 2013). LGBT seniors also have higher rates of disability, mental distress, and a greater propensity for smoking and excessive drinking than others and more likely to be isolated (Fredriksen-Goldsen et al. 2013). If persons require caregiving, it is the family of choice that tends to fulfill this role, but as these caregivers are not covered by the FMLA, providing such care can be a financial hardship. As marriage equality for gay and lesbian couples was only recently put into effect, a large proportion of LGBT older adults tend not to be legally married. This puts them at additional risk as the rights of their caregiving partners may not be recognized or considered.

Institutional care poses further problems with concerns about discrimination, harassment, and mistreatment by staff (Lambda Legal 2011). Moreover, the Medicaid spousal impoverishment protections established in 1988 to protect the home and assets of the spouse of a person in a nursing home do not require that states treat same sex couples in the same way. Consequently, partners may be left financially vulnerable in the community.

Attention to the specific needs of this older population is found in the LGBT Elder Americans Act introduced into the Senate in September 2012 (S.3575). The act would increase federal funding to organizations serving these older adults and their caregivers, collect data on discrimination, include LGBT older adults as a vulnerable population with the greatest economic and social needs under the OAA, prioritize research and development grants for organizations to facilitate access to services, and improve LGBT health and long-term care needs. However, the act has not moved out of committee, and federal recognition of the concerns of this population remains muted. Unquestionably, this is an area where social work advocacy can play a critical role.

\section{Immigrants}

Between the years 1990 and 2010, the number of immigrants in the USA over the age of 65 almost doubled from 2.7 million to nearly 5 million (Leach, 2008-2009). This older group composes $12 \%$ of all immigrants in the country with $73 \%$ naturalized citizens (Migration Policy Institute 2012).

Compared to their native-born peers, older immigrants are more likely to be living in poverty with half having less than $\$ 11,000$ in individual income per year (Migration Policy Institute 2012). Not surprisingly, they depend more on public assistance than those born in the USA with most of this assistance coming from SSI. However, with some exceptions, this assistance, which remains regulated by the states, is only for those who are naturalized citizens or for those who entered the USA before 1996.

Medicare offers benefits only to those who have become citizens and have worked in the USA for at least 10 years. Those who have been permanent residents for 5 years may buy into the program. Medicaid maintains the 5 -year residency requirement for eligibility although states have the option to offer coverage. The 5-year rule also pertains to the Affordable Care Act (ACA) as coverage is limited to older legal residents who have lived in the USA for at least 5 years.

As well as eligibility restrictions, access to services by older immigrants is often impacted by their limited ability to communicate in English (Leach 2009). This increases their dependency on their families who themselves may not be knowledgeable about specific programs. Such dependency also can lead to isolation and depression intensifying needs for mental health care. The multitude of factors impacting older immigrants and their accessibility of health care is a flagrant violation of their rights.

\section{Discussion and Implications}

Older adults are vulnerable to having their human rights violated as age itself is commonly used as a measure of competency and ability. Stereotypes and biases about older people and their functioning abilities contribute to marginalization and discrimination, which implode fundamental human rights associated with freedom, dignity, participation, health, and security. As long as ageism remains unchallenged, it will 
continue as a detriment to policies that support and respect the dignity of older adults.

The implications for the profession are vast as social work's commitment to social justice dictates that it advocate for and promote policies that support the most vulnerable in society (CSWE 2015; NASW 2008, Sec. 6.01). This means moving beyond the needs-based approach, which often provides the basis for social work involvement with older adults, to a rights-based approach that focuses on policies that secure their mandated well-being.

In advocating for policy changes, social workers must use their knowledge and understanding of older adults to influence and educate policy makers to assure that key policies uphold rather than undermine human rights. At the macro level, they can help to advocate for a United Nations Convention on Older People that would give universal recognition to the concerns of this growing population. One way they can strengthen their efforts is by becoming involved in organizations such as National Council on the Aging (NCOA), American Society of Aging (ASA), and American Association of Retired Persons (AARP) strong advocacy institutions that work towards policy changes.

Social workers can utilize their specialized training in social policy analysis, advocacy, and community organizing to lead a national movement to raise public awareness and ensure the human rights of all older adults. In essence, they need to

(i) Identify and engage multiple stakeholders at the local, regional. and national level to work collaboratively.

(ii) Engage for-profit businesses and non-profit organizations who depend on older adult consumers in supporting (financially and in-kind) a national movement.

(iii) Recruit and train older adults to engage in political action.

(iv) Learn from national movements around the globe that are effectively addressing the rights of older adults.

(v) Advocate with elected representatives across the country to protect the rights of older adults and enhance their well-being.

(vi) Engage media to raise awareness and critical consciousness among the general public.

(vii) Collect and disseminate evidence on the impact of social policies on the lives of older adults.

(viii) Build a national consensus and action plan to promote the human rights of all older adults

As human rights advocates, social workers must ensure that policies are fulfilling rights rather than simply addressing needs. As noted earlier, a clear example of this is the lack of Medicare coverage for hearing aids and most dental care. While these may easily be perceived as health-care needs, they are directly connected to human rights as they impact abilities to enjoy full health and actively participate in society.
Utilizing advocacy strategies such as meeting with officials, letters to the editor, testifying at public hearings, and community presentations on human rights and the rights of older adults, social workers can assume leadership roles in promoting rights-based policies. Given their direct involvement with the aging population, they have access to experiences and case studies that can be powerful illustrations of the ways in which policies and services directly impact quality of life, well-being, and rights.

At both the micro and mezzo levels, social workers can help to empower older adults so that their own voices are heard. Encouraging older adults to advocate on issues that impact them through mobilization, organizing, and training and supporting them in their efforts and helping them to perceive needs as rights are important social work roles. Such empowerment increases self-worth and dignity while providing a framework for community participation (Cox 2014).

However, in order for the profession to take a leadership role with regards to the rights of older adults, it is critical that social workers examine their own attitudes and preconceptions of aging. Years ago, one of the pioneers of gerontological social work wrote that without a decisive commitment to aging, free of biases and stereotypes, the training of gerontological practitioners remained uncertain and problematic (Monk 1981). Schools of social work have an important role in undermining these biases by helping to assure that students are offered gerontology courses and that geriatric social work, both clinical and policy practice, is promoted.

By working for social justice and the rights of older adults, social workers can critically impact society through changes that affect those they serve while creating a more just society. But, working for social justice is not easy; it is a struggle that includes all levels of intervention and depends on the belief that rights can be realized (Wronka 2008). This struggle is particularly acute in the realization of the rights of older adults as it impacts both present and future generations.

\section{References}

AARP (2015). With no COLA increase, AARP urges congress to pass Medicare Fix. Retrieved from www. http://www.aarp.org/aboutaarp/press-center/info-10-2015/aarp-urges-congress-to-passmedicare-fix.html. Accessed 13 Apr 2016.

AARP and NAC. (2015). Caregiving in the U.S., annual report. Washington DC: Author.

Alzheimer's Association (2011). Respect for autonomy. Retrieved from $\mathrm{http}: / /$ www.alz.org/documents_custom/statements/Respect_for Autonomy.pdf. Accessed 16 Mar 2016.

Badgett, M, Durson, L., \& Schneebaum, M. (2013). New patterns of poverty in the lesbian, gay, and bisexual community. Los Angeles: UCLA: The Williams Institute. 
Commission on long term care (2013). Report to congress. Retrieved from http://www.medicareadvocacy.org/wp-content/uploads/2014/ 01/Commission-on-Long-Term-Care-Final-Report-9-18-1300042470.pdf. Accessed 13 Feb 2016.

Council on Social Work Education. (2015). Educational policy and accreditation standards for baccalaureate and Master's social work programs. Washington DC: Author.

Cox, C. (2014). Personal and community empowerment for grandparent caregivers. Journal of Family Social Work, 17, 162-174.

Cox, C., \& Pardasani, M. (2013). Alzheimer's in the workplace: a challenge for social social work. Journal of Gerontological Social Work, 56, 643-656.

Cubanski, J., Casillas, G., \& Damico, A. (2015). Poverty among seniors: an updated analysis of national and state level poverty rates under the official and supplemental poverty measures. Los Angeles: Kaiser Family Foundation. Issue Brief Retrieved from http://kff. org/report-section/poverty-among-seniors-issue-brief/. Accessed 18 Nov 2016.

Doron, I., \& Apter, I. (2010). The debate around the need for a new convention on the righs of older persons. The Gerontologist, 50, 5686-5593.

Dragset, J., Eide, G., \& Ranhoff, A. (2013). Anxiety and depression among nursing home residents without cognitive impairment. Scandinavian Journal of Caring Sciences, 27, 872-881.

Fredriksen-Goldsen, K., Kim, K., Barkan, S., Murcao, A., \& HoyEllis, C. (2013). Health disparities among lesbian, gay, and bisexual older adults. American Journal of Public Health, 103, 1802-1809.

Fredriksn-golsen, K, Kimm H., Shiu, C, Golsen.J. amd Emlet, C. (2014). Successful aging among LGBT older adults; Phsyical and mental health-related quality of life by age group, The Gerontoogist, 55, 154-168.

GAO. (2012). Retirement security: women still face challenges, report to the chairman. Special Committee on Aging, Washington DC U.S. Senate.

Gatenio Gabel, S. (2016). A rights-based approach to social policy and analysis. New York: Springer International Publishing.

Genworth (2015). Insights from Genworth's Cost of Care Survey, the cost of long term care, Retrieved from https://pro.genworth.com/ riiproweb/productinfo/pdf/162731.pdf. Accessed 20 Apr 2016.

Ghilarducci, T., \& Moore, K. (2015). Racially disparate effect of raising the retirement age. Schwartz Center for Economic Policy Analysis, The New School for Social Research, Working Paper Series 2015-3.

Help Age International (2010). Strengthening older people's rights: towards a UN convention, Retrieved from http://www.helpage.org/ what-we-do/rights/strengthening-older-peoples-rights-towards-aconvention/. Accessed 15 Feb 2016

Ife, J. (2012). Human rights and social work: towards rights based practice (3rd ed.). New York: Cambridge University Press.

International Federation of Social Workers (2012). Ageing and older adults. Retrieved from http://ifsw.org/policies/ageing-and-olderadults/. Accessed 21 Feb 2017.

International Federation of Social Workers (2014). Global definition of social work. Retrieved from http://ifsw.org/get-involved/globaldefinition-of-social-work/. Accessed 21 Feb 2017.

Kaiser Family Foundation (2011). Implications of a Federal Block Grant Program for Medicaid. April 1. Retrieved from http://kff.org/healthreform/issue-brief/implications-of-a-federal-block-grant-program/. Accessed 3 Jun 2016.

Kaiser Family Foundation (2015). Medicaid in a time of growth and change: Findings from the Annual State Medicaid Budget Survey at a Forum with the National Association of Medicaid Directors, Kaiser Commission on Medicaid and the Uninsured. Retrieved from http://www.kff.org/medicaid/event/medicaid-ina-time-of-growthand-change-findings-from-the-annual-kaiser-50-state-medicaid- budget-survey-at-a-forumwith-thenational-association-of-medicaiddirectors/. Accessed 14 Feb 2017.

Leach, M. (2009). America's older immigrants: a profile. Generations, $32(4), 343-349$.

Lamda Legal (2011). LGBT Seniors raise serious fears about long term care. Retrieved from http://www.lamdalegal.org/dc_20110405 lgbt-elders-raise-serious. Accessed 22 Jun 2016.

Libal, K \& Harding, S. (2015). Human rights-based community practice in the United States, New York: Springer.

Medicare (2015). When Medicare pays for home health care. Retrieved from http://www.medicareinteractive.org/page2.php?topic= counselor\&page=script\&script id=66. Accessed 23 Jun 2016.

Megret, F. (2011). The human rights of older persons: a growing challenge. Human Rights Law Review, 11, 37-66.

Migration Policy Institute (2012). Pyramids of U.S. immigrant and native born populations, 1970-present. Retrieved from http://www. migrationpolicy.org/programs/data-hub/ud-immigration-trends\# agesex. Accessed 15 May 2016.

Monk, A. (1981). Social work with the aged: principles of practice. Social Work, 27, 65-78.

Moye, J., \& Naik, A. (2011). Preserving rights for individuals facing guardianship. Journal of the American Medical Association, 305, 936-937.

National Association of Social Workers. (2008). Code of ethics. Washington DC: Author.

National Association of Social Workers (2014). Aging. Retrieved from https://www.socialworkers.org/pressroom/features/issue/ aging.asp. Accessed 13 Mar 2016.

National Women's Law Center (2015). What the new census bureau data say about women. Retrieved from https://nwlc.org/blog/what-newcensus-bureau-data-say-about-women/. Accessed 11 Mar 2017.

National Council on Aging (NCOA). (2016). Economic security for seniors facts. Washington DC: Author.

Ng, T., Harrington, C., \& Kitchener, M. (2010). Medicare and Medicaid in long term care. Health Affairs, 29, 22-28.

Ortman, C., Velkoff, A., \& Hogan, H. (2014). An aging nation: the older population in the United States, Current Population Reports, p25(114-.US Census).

Ottenstein, R., \& Jacobson, J. (2006). Gaining a seat at the table. Journal of Employee Assistance, 36, 13-15.

Paradise, J. (2015). Medicaid moving forward. March 9, 2015. http://kff. org/health-reform/issue-brief/medicaid-moving-forward/. Accessed 3 Jun 2015.

Reamer, F. (2005). The challenge of paternalism in social work, Social Work Today. Retrieved from http://www.socialworktoday.com/ news/eoe_0105.shtml. Accessed 14 May 2016.

Rix, S. (2013). The employment situation, may 2013: some good news for older workers tempered by continuing problems, fact sheet 284, AARP public policy institute. Washington DC: AARP.

Smith Fitzpatrick, C. (2014). Age discrimination, AARP Office of Policy Integration. Washington DC: AARP.

SSA (2014). Social Security: Basic Facts. Retrieved from http://www.ssa. gov/news/press/basicfact.html. Accessed 18 May 2016.

SSA (2015). SSI Federal Payment Amounts for 2015. Retrieved from http://www.ssa.gov/OACT/COLA/SSI.html. Accessed 18 May 2016.

U.S. Equal Employment Opportunity Commission (2015). Enforcement and Litigation Statistics. Retrieved from http://www.eeoc.gov/eeoc/ statistics/enforcement/adea.cfm. Accessed 13 Jan 2016.

Uekert, B., \& Van Duizend, R. (2010). Adult guardianships: a best guess national estimate and the momentum for reform. Retrieved from http://courtnewsohio.gov/happening/2016/adultGuardianshipEd 062316.pdf. Accessed 14 May 2016.

United Nations. (2002). Political declaration and Madrid international plan of action on ageing, second world assembly on ageing. New York: United Nations. 
United Nations. (2013). World population aging. New York: Author.

United Nations (1991). Human Rights Council, Report of the Independent Experts on the Enjoyment of all human rights by older persons. Retrieved from https://documents-dds-ny.un.org/doc/ UNDOC/GEN/G16/147/83/PDF/G1614783.pdf?OpenElement. Accessed 22 May 2016.

von Schader, S and Nazaro, Z (2015). Employer characterstics associated with discrimination charges under the Americans with Disabilities Act, Journal of Disability Policy Studies, 26, 153-163.

Waid, M. (2016). Social security: a key retirement income source for older minorities. Washington, DC: AARP Public Policy Institute.

Women's National Law Center (2014). Whose poverty rate increased last year? Older Women's. Retrieved from https://nwlc.org/blog/whose- poverty-rate-increased-last-year-older-womens/. Accessed 22 Mar 2017.

WOW (Wider Opportunities for Women) (2012). Doing without: economic insecurity and older Americans, No.2. Retrieved from h t t p : // w w w. w o w o n l n e. or g/ d o c u ments/ DoingWithoutRankingofthestates2.22.11.pdf. Accessed 25 Nov 2016.

Wright, J.L., (2014). Making mediation work in guardianship proceedings: protecting and enhancing the voice, rights, and well-being of elders. Legal Studies Research Paper No. 14-27. Retrived from: http://ssrn.com/abstract=2477111. Accessed 18 Dec 2016.

Wronka, J. (2008). Human rights and social justice. Thousand Oaks: Sage. 